WellBeing International

WBI Studies Repository

$1-14-2013$

\title{
Flooring and Driving Conditions During Road Transport Influence the Behavioural Expression of Cattle
}

\author{
Catherine A. Stockman \\ Murdoch University \\ Teresa Collins \\ Murdoch University \\ Anne L. Barnes \\ Murdoch University \\ David Miller \\ Murdoch University \\ Sarah L. Wickham \\ Murdoch University
}

See next page for additional authors

Follow this and additional works at: https://www.wellbeingintlstudiesrepository.org/acwp_asie

Part of the Agribusiness Commons, Animal Studies Commons, and the Operations and Supply Chain Management Commons

\section{Recommended Citation}

Stockman, C. A., Collins, T., Barnes, A. L., Miller, D., Wickham, S. L., Beatty, D. T., ... \& Fleming, P. A. (2013). Flooring and driving conditions during road transport influence the behavioural expression of cattle. Applied Animal Behaviour Science, 143(1), 18-30.

This material is brought to you for free and open access by WellBeing International. It has been accepted for inclusion by an authorized administrator of the WBI Studies Repository. For more information, please contact wbisr-info@wellbeingintl.org.

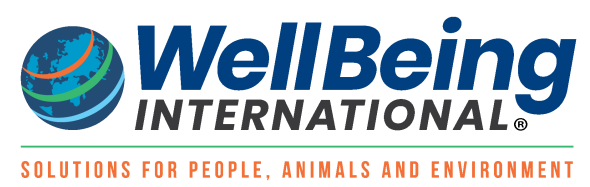




\section{Authors}

Catherine A. Stockman, Teresa Collins, Anne L. Barnes, David Miller, Sarah L. Wickham, David T. Beatty, Dominique Blache, Françoise Wemelsfelder, and Patricia A. Fleming 


\section{Flooring and Driving Conditions During Road Transport Influence the Behavioural Expression of Cattle}

Catherine. A. Stockman ${ }^{1}$, Teresa Collins ${ }^{1}$, Anne L. Barnes ${ }^{1}$, David Miller ${ }^{1}$, Sarah L. Wickham ${ }^{1}$, David T. Beatty ${ }^{2}$, Dominique Blache ${ }^{3}$, Francoise Wemelsfelder ${ }^{4}$, Patricia A. Fleming ${ }^{1}$

${ }^{1}$ Murdoch University

${ }^{2}$ Meat \& Livestock Australia

${ }^{3}$ The University of Western Australia

${ }^{4}$ Scottish Agricultural College

\section{KEYWORDS}

free choice profiling, generalised procrustes analysis, physiology, QBA, road transport, stress

\section{ABSTRACT}

This study examined whether observers could distinguish between cattle that were exposed to various road transport conditions: Experiment 1 compared a manipulated flooring treatment (non-grip flooring, NG) with a control transport event (grip flooring, G) and Experiment 2 compared a manipulated driving style (stop-start driving, SS) with a control transport event of smooth, continuous (C) driving. The behavioural expression of cattle was assessed through the process of Qualitative Behavioural Assessment (QBA), and these assessments were tested for correlation with various physiological parameters. Fourteen Angus steers were assessed. Blood samples were collected immediately before and after transport, and heart rate and core body temperature were measured continuously throughout each transport event. Continuous video footage recorded during each transport event was edited to isolate short clips of individual animals which were randomly ordered and shown to observers for QBA and analysis by Generalised Procrustes Analysis (GPA) which identifies common dimensions of behavioural expression. There was significant consensus amongst 39 observers in their assessment of behavioural expression of the cattle $(P<0.001)$. In Experiment 1, observers scored cattle exposed to NG flooring during road transport relatively higher (on visual analogue scales) for terms such as 'agitated', 'restless' and 'anxious' compared with cattle exposed to G flooring, which were scored higher for 'calm', 'comfortable' and 'relaxed' (GPA dimension 1, $P<0.001)$. In Experiment 2, cattle exposed to SS driving received higher average GPA dimension 1 scores $(P<0.01)$ and higher GPA dimension 2 scores $(P<$ 0.05). These cattle were therefore scored relatively higher for terms such as 'restless', 'agitated' and 'scared' (GPA dimension 1) or 'curious', 'interested' and 'inquisitive' (GPA dimension 2) compared with cattle exposed to $C$ driving, which were scored higher for 'calm', 'relaxed' and 'comfortable' (GPA dimension 1), or 'stressed', 'tense' and 'alert' (GPA dimension 2). There were some significant correlations between physiological responses and behavioural expression of animals for both experiments, with informative correlations between the different dimensions of behavioural expression and white blood cell counts, red blood cell parameters and heart rate. For example, the neutrophil: lymphocyte ratio, a typical marker of stress in ruminants, was elevated in cattle that were described as more 'agitated', 'restless' and 'anxious' (G-NG flooring: GPA dimension 1) or 'stressed', 'tense' and 'alert' 
(C-SS driving: GPA dimension 2). These results suggest that the QBA process captured behavioural manifestations of stress in cattle. We conclude that QBA is a valuable method of assessing cattle welfare under the conditions tested since there was significant consensus in the ability of human observers to interpret behavioural expression of cattle during these experimental conditions (i.e. QBA is repeatable), observers could distinguish between transport treatments on the basis of the animals' QBA scores, and these scores were correlated with meaningful physiological measures.

\section{Introduction}

Most cattle are transported at least once in their lifetime (e.g. from source to sale or slaughter) and may be exposed to environmental stressors that can compromise both welfare and productivity during transport. The welfare of livestock during road transport has received much attention, with research largely aimed at reducing mortality, bruising, and occurrences of low quality meat (e.g. Grigor et al., 2001; Knowles, 1999; Le Neindre et al., 2001; Tarrant, 1990; Trunkfield and Broom, 1990). Increased public scrutiny relating to welfare of animals during transport has prompted research addressing environmental conditions during transport, including length of time in transit (Warriss et al., 1995), stocking rate (Eldridge et al., 1988), driving pattern (Eldridge et al., 1988) and stability (Tarrant, 1990), as well as variability in responses to transport of different types of animals, e.g. presence of horns (Wythes, 1985) and age of animal (Barnes et al., 1975).

Although a great deal of research has investigated methods of improving animal welfare during road transport, there is still a need for development of welfare assessment methods that can be used to monitor animal welfare under industry situations. Development of reliable welfare assessment methods will allow improved animal management and industry regulation of welfare. Physical changes in an animal, such as injury and mortality, are generally acknowledged to be major indicators of poor welfare. However, for some stakeholders, good welfare implies much more than good health and low risk of mortality, and good animal welfare results both from an absence of negative experiences as well as the presence of positive affective states (Kendrick, 2007; Mellor, 2012; Yeates and Main, 2008). Physiological responses are widely regarded by the scientific community as reliable measures of homeostatic response to stress and therefore indicators of animal welfare (Dawkins, 2003). However, physiological measures are often expensive and need to be carried out under carefully-controlled conditions by experienced animal handlers and practitioners. Assessing welfare via physiological responses is therefore difficult to implement under normal industry conditions, can be highly invasive and the process of measurement, itself, may influence the outcome. Finally, the link between physiological changes in normal everyday functioning also needs to be accounted for if these measures are to be used as indicators of animal welfare. For example, anticipation of food and exercise result in increased respiratory rate, corticosteroids and heart rate (e.g. Honma et al., 1983; Sutton and Casey, 1975; Thomas and Pearson, 1986). Also, many parameters also vary with time of day, temperature and breeding condition (e.g. Piccione and Caola, 2002).

The behaviour of animals may be important to enable valid interpretation of animal welfare. In the present study, assessment of animal behavioural expression is examined to test its validity as a potential welfare assessment method. Qualitative Behavioural Assessment (QBA) is a method that integrates observations of the whole animal, and is potentially a cheap and flexible method of welfare assessment. Previous studies in cattle have revealed differences in behavioural expression between dairy cattle under various housing conditions (Rousing and Wemelsfelder, 2006), and have investigated the correlation of QBA 
measures with clinical assessments of veal calves (Brscic et al., 2009). A study of cattle during transport indicated that there were significant differences in the behavioural expression of animals when they were naïve to, or habituated to, road transport (Stockman et al., 2011).

As part of the process of validation of QBA as an objective, reliable and repeatable method of animal welfare assessment, we compared QBA for cattle that exhibited a range of behaviour and compared these measures with physiological parameters. Road transport was selected as the model because it is a well known stressor for livestock (Kent and Ewbank, 1983; Murata and Hirose, 1990, 1991; Tarrant et al., 1992), and the environment can be manipulated and is therefore to some degree controllable experimentally. The physical environment was manipulated through altered flooring structure (Experiment 1) and different driving styles (Experiment 2). The aims of these experiments were to:

1. determine whether observers could reach consensus in their assessment of the behavioural expression of cattle;

2. determine whether observers could distinguish between experimental treatment groups based on the animals' behavioural expression; and

3. determine how QBA scores correlate with physiological measures that are indicative of the animals' physiological and affective states.

\section{Materials and methods}

\subsection{1 Animals and transportation}

Fourteen Angus steers (12 months of age; $347 \pm 11 \mathrm{~kg}$ ) were selected randomly from a herd that had the same sire. During the study, cattle were housed in a single paddock and group fed with a feedlot ration at 3\% live weight/head/day (Easy Beef, Milne Agrigroup, Welshpool, Western Australia, 14.5\% crude protein and $11.0 \mathrm{MJ} / \mathrm{kg}$ metabolisable energy). The same cattle had been used for a previous study examining their behaviour when they were first transported (transport-naïve) or habituated to road transport (Stockman et al., 2011).

Cattle were transported by the same driver, in a car-drawn, double-axel trailer with a stock cage (3.66 $\times$ $2.05 \mathrm{~m}$ ). Stocking rate on the trailer was within industry recommendations $\left(1.07 \mathrm{~m}^{2} / \mathrm{head}\right.$ ) (Standing Committee on Agricultural and Resource Management, 2002). Due to logistical constraints, cattle were transported in two groups of seven (transport groups 1 and 2), with the same individuals making up each group on successive days. All transport events were $90 \mathrm{~min}$ in length.

Environmental temperature $\left({ }^{\circ} \mathrm{C}\right.$ ) and relative humidity (\%) were recorded (every $2 \mathrm{~s}$ ) during transport (Onset HOBO H8 Pros, \#H08-032-IS, OneTemp Pty Ltd, Parramatta, NSW, Australia) to ensure that environmental temperature on each experimental transport event was not significantly different. Each logger was positioned at cattle head height, with one at the front and one at the rear of the trailer. These data were used to dismiss transport events where the temperature varied by more than $5{ }^{\circ} \mathrm{C}$ from the mean; no further analyses were carried out.

The two challenges applied in this study, which comprise two distinct experiments in regard to analyses and interpretation, were exposure to altered flooring structure (Experiment 1), and exposure to different driving styles (Experiment 2) during road transport. In Experiment 1, a non-grip flooring (NG) transport event was compared with a grip-flooring $(G)$ event. In Experiment 2, we compared a stop-start driving (SS) transport with a continuous driving (C) event. For video footage for QBA, core temperature $\left(\mathrm{T}_{\text {core }}\right)$ and heart rate (HR) data, we used data recorded within the first 30 min after departure (Experiment 1$)$ or within the final 30 min (Experiment 2), as we predicted greatest effects of the experimental treatments at the commencement and end stages of the transport events, respectively. 
The trailer had a solid roof and the walls were constructed from metal slats, allowing plentiful ventilation. The floor was cleaned following each transport event. The trailer had a metal-grate placed over the entire floor area for additional foot stability. The grate consisted of a grid of horizontal and vertical 10-mm steel rods, spaced $100 \mathrm{~mm}$ apart, placed directly upon the floor (and therefore was raised a maximum of 20 $\mathrm{mm}$ from the steel plate of the floor). The grate was in place for all transport events except the 'non-grip' (NG) event. For Experiment 1, the NG transport event was compared with a transport event with the floor grate in place ('grip', G).

For Experiment 2, we manipulated driving style, comparing smooth, continuous (C) driving with SS driving. Except for the $\mathrm{C}$ and $\mathrm{SS}$ transport events, the route included approximately $65 \mathrm{~km}$ of main roads (where the speed limit was between 50 and $70 \mathrm{~km} / \mathrm{h}$ ) and highways (speed limit between 70 and 100 $\mathrm{km} / \mathrm{h}$ ). For Experiment 2, the $C$ driving route followed freeways and country roads with minimal stops and an average speed of $85 \mathrm{~km} / \mathrm{h}$. This was compared with the SS driving event, where the route followed suburban streets with frequents stops at intersections and frequent turns; speed averaged $40 \mathrm{~km} / \mathrm{h}$.

The experimental period spanned 28 days (cattle were not transported every day; e.g. we did not transport them during wet weather) (Table 1). During this period, each group was initially transported eight times to habituate the cattle to the transport process. For experimental transport events, groups 1 and 2 were transported on different days but at the same time of day. Note that the $G$ and NG transport events (Experiment 1), and the C and SS events (Experiment 1) (preceded by a further habituation event), occurred on consecutive days for each transport group (Table 1).

\subsection{Physiology}

We carried out measurements of physiological variables which have been used by various authors (reviewed by Knowles, 1999) as indicators of altered physiological state during transport, including body temperature, heart rate, metabolites, hormones, haematological and immune responses. For example, transport-naïve cattle demonstrate increased core temperature, increased concentrations of cortisol and glucose, and increased neutrophil: lymphocyte ratio compared to samples taken from the animals once habituated to transport (Stockman et al., 2011). Similarly, transport-naïve sheep demonstrate increased core temperature, heart rate, plasma cortisol, white blood cell count and neutrophil: lymphocyte ratio compared with when they have become habituated to the process (Wickham et al., 2012). Many of these measures link with activation of the hypothalamic-pituitary-adrenal axis and an immune system response due to stress. Even if physiological measures did not show significant transport treatment effects (i.e. individual variability may exceed the differences between treatment groups), individual differences in physiological responses may still be correlated with the behavioural expression scores.

\subsubsection{Core temperature}

Temperature loggers (iButtons, Maxim Integrated Products, Sunnyvale, CA, USA; accuracy $\pm 0.1{ }^{\circ} \mathrm{C}$ ) were surgically implanted into the peritoneal cavity in the region of the right paralumbar fossa of each animal, as described in Beatty et al. (2006). The surgery took place 16 days before the first transport event, allowing time for recovery. Retrieval of the loggers took place at slaughter, following completion of the experiment; retrieval was unsuccessful for two individuals (therefore $n=12$ for temperature data for both experiments). The loggers were set to record core body temperature ( $\left.T_{\text {core }}\right)$ every 2 min for the duration of the experiment and average and maximum $T_{\text {core }}$ values were retrieved for the first 30 min after departure for Experiment 1 and the last 30 min for Experiment 2 ('during' transport values). These were compared with average and maximum $\mathrm{T}_{\text {core }}$ for the same time of day averaged over three non-transport, non-handling days (weekends when these animals were in their home paddock; Table 1). 


\subsubsection{Blood sampling and analysis}

Blood was collected by the same person for each experimental transport event (Table 1) using jugular venipuncture. As the collection of blood had the potential to influence cattle behaviour, blood was not collected during transport but rather 'before' and 'after' the transport event. Cattle were moved from their home paddock to a holding yard adjoining the crush and loading ramp and left to settle for $1 \mathrm{~h}$. During this time, feed was withdrawn but water was available ad libitum. They were then passed through a crush allowing the 'before' transport blood sample to be taken and heart rate belts to be fitted (see below). The animals were held in an adjacent holding yard until the whole group had been sampled (approximately 15 $\mathrm{min}$ ); cattle were then loaded as a group onto the trailer (without the use of electric prods) for immediate departure. 'After' transport blood samples were collected once cattle were unloaded, immediately following the experimental transport event (approximately $15 \mathrm{~min}$ to sample the group).

Table 1. Timetable of the transportation events during 28 days (d).

\begin{tabular}{|c|c|c|c|c|c|c|c|c|c|c|c|c|c|c|}
\hline Week & & Monday & & Tuesday & & Wednesday & & Thursday & & Friday & & Saturday & & Sunday \\
\hline 1 & & & & & & & $\mathrm{~d} 1$ & $\mathrm{H} 1$ & $\mathrm{~d} 2$ & $\mathrm{H} 2$ & d3 & NT & $\mathrm{d} 4$ & NT \\
\hline 2 & d5 & & d6 & H 1 & d7 & $\mathrm{H} 1$ & d8 & $\mathrm{H} 1$ & d9 & H $1 \& 2$ & $\mathrm{~d} 10$ & NT & $\mathrm{d} 11$ & NT \\
\hline 3 & $\mathrm{~d} 12$ & H $1 \& 2$ & $\mathrm{~d} 13$ & H $1 \& 2$ & $\mathrm{~d} 14$ & H $1 \& 2$ & $\mathrm{~d} 15$ & G 1, pm: H2 & d16 & NG 1, pm: H2 & $\mathrm{d} 17$ & NT & $\mathrm{d} 18$ & NT \\
\hline 4 & d19 & G 2 & $\mathrm{~d} 20$ & G 2 & $\mathrm{~d} 21$ & NG 2, pm: H 1 & $\mathrm{~d} 22$ & C 1 & d23 & SS 1 & $\mathrm{~d} 24$ & NT & $\mathrm{d} 25$ & NT \\
\hline 5 & $\mathrm{~d} 26$ & C 2 & $\mathrm{~d} 27$ & $\mathrm{C} 2$ & $\mathrm{~d} 28$ & SS 2 & & & & & & & & \\
\hline
\end{tabular}

$\mathrm{H}$ : Habituation days, NT: non-transport handling days. Cattle were blood sampled immediately before and after the experimental transport events [shown in bold: grip flooring (G), non-grip flooring (NG), continuous driving (C) and stop-start driving (SS)], heart rate data and video footage were collected during these transport events. 1 and 2 refer to the two transport groups.

H 1 \& 2 indicates that both groups were transported on the same day; groups 1 and 2 were alternated between mornings (am) and afternoons (pm).

Whole blood was collected in EDTA tubes, immediately placed on ice and then refrigerated and used for analysis of complete haematological profile within $24 \mathrm{~h}$ of collection. Haematological variables analysed using the Bayer Advia 120 Hematology System (with veterinary software; Siemens Healthcare Diagnostics Inc., Tarrytown, New York, USA) were white blood cell count (WBC), red blood cell count (RBC), haematocrit (HCT), and the proportions of neutrophils (\%), lymphotcytes (\%), eosinophils (\%), basophils (\%) and monocytes (\%). The proportion of neutrophils: lymphocytes was calculated for analysis since values for these cell types were auto correlated and the neutrophil: lymphocyte ratio is a common measure of ruminant stress (Jones and Allison, 2007).

A second blood sample was taken in EDTA tubes (also immediately placed on ice) and, within 15 min of collection from the last animal, was centrifuged for $15 \mathrm{~min}$ at $604 \mathrm{~g}$ and the plasma removed and frozen before batch analysis for cortisol, insulin-like growth factor (IGF-1), prolactin, $\beta$-hydroxy-butyrate and glucose. Plasma insulin were measured in duplicate by a double-antibody radioimmunoassay (Tindal et al., 1978). Plasma IGF-I was assayed in duplicate by double-antibody radioimmunoassay with human recombinant IGF-I (ARM4050, Amersham-Pharmacia Biotech, Buckinghamshire, England) and antihuman IGF-I antiserum (AFP4892898, National Hormone and Pituitary Program of the National Institute of Diabetes and Digestive and Kidney Diseases, California, USA) following acid-ethanol extraction and cryoprecipitation (Breier et al., 1991). Plasma cortisol concentration was determined using a commercial radioimmunoassay kit (Clinical Assays ${ }^{\mathrm{TM}}$, GammaCoat $^{\mathrm{TM}}$, Cortisol $125 \mathrm{I}$ RIA Kit, DiaSorin, USA). All samples were processed in a single assay and the limit of detection was insulin, $0.5 \mu \mathrm{U} / \mathrm{mL}$; IGF- 1, $0.05 \mathrm{ng} / \mathrm{mL}$; and cortisol, $3.5 \mathrm{nmol} / \mathrm{L}$. The assay included six replicates of three control samples containing insulin: $10.62,3.89$ and $2.49 \mu \mathrm{U} / \mathrm{mL}$ (intra-assay coefficients of variation, CV: $3.9 \%, 1.9 \%$ and $5.4 \%$.), or two control samples for IGF-I containing 0.39 and $2.14 \mathrm{ng} / \mathrm{mL}$ (intra-assay CV: $7.3 \%$ and 
2.3\%), and cortisol: 46.1 and $85.65 \mathrm{nmol} / \mathrm{L}$ (intra-assay $\mathrm{CV}$ : $5.0 \%$ and $2.1 \%$ ). Plasma ACTH concentration was measured using a solid-phase two-site chemiluminescent enzyme immunometric assay (Scott-Moncrieff et al., 2003). The limit of detection was $5 \mathrm{pg} / \mathrm{mL}$ and a working range of 12-1250 $\mathrm{pg} / \mathrm{mL}$. Plasma glucose (Olympus kit, Cat. No. OSR6121, Europa GmBH, Hamburg, Germany) and plasma beta-hydroxy-butyrate (Randox kit, Ranbut, Cat. No. RB1007, Crumlin, County Antrim, United Kingdom) concentrations were determined using a commercial kit run on an Olympus AU400 automated chemistry analyser (Olympus Optical Co. Ltd., Olympus, Hamburg, Germany).

\subsubsection{Heart rate}

Heart rate (HR, beats per min) was recorded (every $5 \mathrm{~s}$ ) during the experimental transport events with external heart rate monitors (Polar Equine S625X, Polar Electro Oy, Adelaide, South Australia). Custommade elastic belts were used to fix electrodes in place, depending on the animal's size. Heart rate monitors were fitted immediately after the 'before' transport blood sampling and were removed following the 'after' transport blood sampling. Cattle were also fitted with the heart rate belts for habituation transport events to ensure habituation to the fitting and wearing of the belts. HR data were averaged for the first $30 \mathrm{~min}$ after departure during the $\mathrm{G}$ and NG transport treatment ('during' transport) and were compared for HR data collected 5-10 min before the animals were loaded ('before' transport). HR data were not reliably obtained from any animals during the $\mathrm{C}$ and SS treatments.

\subsubsection{Statistical analysis}

The physiological data did not violate the assumptions of parametric analyses (Levene's test and Shapiro-Wilk's W test). Physiological data were analysed by two-way repeated-measures ANOVA (R-M ANOVA; Statistica 9.0, StatSoft, Tulsa, Oklahoma, USA) for each experiment separately, with time (see below) and treatment (Experiment 1: NG vs. G flooring, or Experiment 2: SS vs. C driving) as the repeated dependent measures, and transport group (transport groups 1 or 2) included as a random factor. For hormones, metabolites and haematological parameters, measures taken 'before' transport were compared with those collected 'after' transport (effect: 'time'). For $\mathrm{T}_{\text {core, }}$ 'during' transport values were compared with values at the same time of day over non-transport, non-handling days (effect: 'time'). Due to lost contact and interference of heart rate monitors, reliable data were obtained for NG: $n=4$ and G: $n=4$ and repeated-measures analysis was not possible; these data were analysed by one-way ANOVA.

\subsection{Qualitative Behavioural Assessment (QBA)}

\subsubsection{Video clip selection}

Video footage (15 frames per $s$ ) was recorded during transport of cattle with four digital cameras (Panasonic SDR-H250 camcorders, Belrose, New South Wales (NSW), Australia) fixed to the front and back of the trailer, above cattle head height. The first available suitable clip was selected for each individual to represent its behavior within the first 30 min after departure for Experiment 1 (G-NG flooring) and within the final $30 \mathrm{~min}$ for Experiment 2 (C-SS driving style), as we predicted greatest effects of the experimental treatments at the commencement and end stages of the transport events, respectively. Clip suitability was determined by clip duration (15 to $30 \mathrm{~s}$ long), and the visibility of the animal (head and shoulders visible). The cattle often held their heads down during transport and therefore, for most animals, there was only one suitable clip of adequate length and quality available. Individuals were identified using numbers printed on the outside of the heart rate belts. The 28 clips for Experiment 1 and the 28 clips for Experiment 2 (14 clips - one for each of the 14 individuals for each of NG, G, SS and C transport events) were edited to highlight individual focal cattle by increasing the opacity of the 
surrounding animals in the same frame (Adobe Premiere Pro CS3 and Adobe After Effects CS3, San Jose, California, USA).

\subsection{2. $Q B A$ sessions}

Staff and students from two Western Australian Universities (Murdoch University and University of Western Australia) and livestock professionals (e.g. Department of Agriculture \& Food, Western Australia) were recruited by targeted advertising on notice boards and email and accepting all 39 persons that responded ( $n=15$ university students, $n=17$ livestock industry professionals and $n=7$ general public; 12 male and 27 female). Importantly, a recent study has demonstrated that despite different backgrounds and experience, people can reach consensus in their assessments using QBA (Wemelsfelder et al., 2012). Each observer was required to attend three sessions on campus or by correspondence. Observers were given detailed instructions on completing the sessions but were not told about the experimental treatments or that the cattle were being transported. The observers could not see the floor of the trailer in the field of view, and the vehicle was moving in all clips. The sessions are detailed below (Sections 2.3.2.1 and 2.3.2.2) and follow methodology of previous QBA studies (e.g. Rousing and Wemelsfelder, 2006; Wemelsfelder and Lawrence, 2001). This methodology has been found to be both reliable and repeatable (Wemelsfelder and Lawrence, 2001).

2.3.2.1. Term generation (session 1). Observers were shown 15 video clips of individual experimental cattle demonstrating a wide range of behaviour to allow observers to describe as many aspects of their expressive repertoire as possible. These clips included some of the experimental footage but also additional footage of these animals that was not included in the quantification sessions; below. After watching each clip, observers were given 2 min to write down any words that they thought described that animal's behavioural expression. There was no limit imposed to the number of descriptive terms an observer could generate, but terms needed to describe not what the animal was doing (i.e. physical descriptions of the animal such as vocalising, chewing, tail flicking), but how the animal was doing it. Subsequent editing of the descriptive terms by the experimenters was carried out to remove terms that described actions, and terms that were in the negative form were transformed to the positive for ease of scoring (e.g. 'unhappy' became 'happy'). Each descriptive term was attached to a 100-mm visual analogue scale (minimum $=0 \mathrm{~mm}$ to maximum $=100 \mathrm{~mm}$ ). The lists of terms were alphabetically arranged and terms with similar meaning were not listed one after the other e.g. frightened, scared. This was to encourage the observer to score terms on their own merit rather than purposefully replicating scores for words of similar meaning.

2.3.2.2. Quantification (sessions 2 and 3). Observers viewed and scored the experimental video clips using their own unique list of descriptive terms. In session 2, observers viewed 28 clips for Experiment 1 (G-NG flooring) and in session 3, observers viewed 28 clips for Experiment 2 (CSS driving style). Before session 2, observers were given detailed instructions on how to score each animal's expression using the visual analogue scale: they were told to think of the distance between the zero-point and their mark on the scale as reflecting the intensity of the animal's expression.

\subsubsection{Statistical analysis.}

The visual analogue scales were scored as the distance from the start $(0 \mathrm{~mm}$ representing minimum values for that term) to where the observer had made a mark (measured in $\mathrm{mm}$, up to a maximum of 100 $\mathrm{mm}$ ) against each descriptive term. These measurements were entered into separate Microsoft Excel (Microsoft Excel 2003, Redmond, Washington, USA) worksheets for each individual observer. Data for the G-NG clips viewed in session 2 (Experiment 1) were analysed by Generalised Procrustes Analysis (GPA) independently from the C-SS clips viewed in session 3 (Experiment 2). 
GPA was carried out with Genstat as part of a specialized software edition written for Françoise Wemelsfelder (Genstat 2008, VSN International, Hemel Hempstead, Hertfordshire, UK; Wemelsfelder et al., 2000). See Wemelsfelder et al. (2000) for a detailed description of (GPA) procedures. Briefly summarised, GPA calculates a consensus or 'best fit' profile between observer assessments through complex pattern matching. The number of dimensions of the consensus profile is then reduced to several main dimensions (usually two or three) explaining the variation between animals through Principle Components Analysis (PCA). The meaning of each GPA dimension is interpreted by analysis of the correlations between the consensus scores and each individual observers' terms. Terms attributed correlation coefficients close to zero did not contribute to the description of the consensus dimension, but terms that are strongly positively or negatively correlated with the axis are descriptive terms that would have contributed to mathematical calculation of the consensus dimension. These terms are then tabulated.

2.3.3.1. Validity of the $Q B A$ consensus. A Procrustes Statistic can be calculated which indicates the degree of consensus (i.e. the percentage of variation explained between observers) that was achieved. Whether this consensus is a significant feature of the data set, or, alternatively, an artefact of the Procrustean calculation procedures, is determined through a randomisation test (Dijksterhuis and Heiser, 1995). This procedure rearranges at random each observer's scores and produces new permutated data matrices. By applying GPA to these permutated matrices, a 'randomised' profile is calculated. This procedure is repeated 100 times, providing a distribution of the Procrustes Statistic indicating how likely it is to find an observer consensus based on chance alone. Subsequently a one-way t-test is used to determine whether the actual observer consensus profile falls significantly outside the distribution of randomised profiles.

2.3.3.2. Treatment effects in $Q B A$ scores. Each clip viewed is ultimately attributed a quantitative score for each of the GPA consensus dimensions. These GPA scores did not violate the assumptions of parametric analyses (Levene's test and Shapiro-Wilk's W test). To investigate treatment effects, GPA scores for each dimension were analysed using repeated measures ANOVA, with the scores for each individual for the respective treatments compared as the repeated-measures for each of the experiments (i.e. Experiment 1: G vs. NG flooring, or Experiment 2: C vs. SS driving). Transport group was included as a random factor (transport groups 1 and 2).

2.3.3.3. Comparison between QBA scores and physiological measures. GPA dimension scores were compared with physiological responses for each transport event for each individual animal by Pearson's correlation (Microsoft Excel 2003, Redmond, Washington, USA). The physiological response was expressed as the change in each parameter due to transport to obtain a single measure for comparison with the GPA scores. For hormones, metabolites and haematological parameters, the change due to transport was calculated as a proportion of 'after' transport to 'before' transport values. The change in $\mathrm{T}_{\text {core }}$ due to transport was calculated using 'during' transport values [mean of first 30 min after departure for Experiment 1 (G-NG flooring) and mean of the final 30 min for Experiment 2 (C-SS driving style)] as a proportion of the means of eight nontransport, non-handling days at the same time of day for the same individual. The change in HR due to transport was calculated for individual animals as mean values 'during' transport as a proportion of 'before' transport values.

\section{Results}

The 39 observers participating in this study generated a total of 180 unique terms to describe the cattle they were shown, with an average of $17 \pm 7$ (range 9-47) terms per observer. Fig. 1 shows an example of one observer's terms graphed against GPA dimension 1 and 2 for the flooring treatment Experiment 1 (Fig. 1a) and the driving style Experiment 2 (Fig. 1b). Terms with the strongest correlation with each of the 
GPA dimensions are shown in Table 2. The important differences in physiology (Tables 3 and 4) were those that demonstrated a significant Treatment $\times$ Time interaction, which would reflect that the experimental treatments resulted in differing physiology. These are discussed below in respect to each experiment.

\subsection{Experiment 1: grip vs. non-grip flooring}

\subsubsection{Physiology}

A summary of the raw values, results of R-M ANOVA and correlation with GPA dimension scores is given in Table 3.

A significant treatment $\times$ time interaction was found for prolactin, with a substantial decrease over time in prolactin concentration for cattle exposed to NG flooring. There was also a treatment $\times$ time interaction for white blood cell count and neutrophil numbers, where the elevation over time due to transport was less pronounced for NG than for the $\mathrm{G}$ treatment.

Being transported (i.e. a significant time effect: before transport vs. after transport) resulted in a decrease in monocyte count, $\beta$-hydroxy butyrate and prolactin concentrations, as well as an increase in WBC, neutrophil count, neutrophil: lymphocyte ratio and Tcore.

\subsubsection{Qualitative Behavioural Assessment}

The Procrustes Statistic generated from the GPA analysis of the G-NG treatments was $44.7 \%$ and this differed significantly $\left(t_{99}=61.3, P<0.001\right)$ from the mean randomised profile $(32.3 \pm 0.2 \%)$, indicating significant consensus between observers in their use of descriptive terms to quantify the behavioural expression of these cattle. Three main GPA dimensions were identified, explaining a total of $63.7 \%$ of the variation between animals (Table 2).

Terms with the strongest correlation with each of the GPA dimensions are shown in Table 2. For GPA dimension 1, low values were associated with terms such as 'calm', 'comfortable' and 'relaxed' and high values with terms such as 'agitated', 'restless' and 'anxious'. For GPA dimension 2, low values were associated with terms such as 'curious', 'interested' and 'alert', and high values with terms such as 'angry', 'nervous' and 'upset'. For GPA dimension 3, low values were associated with terms such as 'nervous', 'bored' and 'worried' and high values with terms such as 'annoyed', 'stressed' and 'distressed'.

The positions of individual cattle on the first two GPA dimensions are shown in Fig. 2a. Cattle on NG flooring had a significantly greater GPA score on dimension $1\left(F_{1,13}=15.09, P<0.001\right)$ than cattle on $G$ flooring; however there were no treatment effects on GPA dimensions $2\left(F_{1,13}=0.261, P=0.619\right)$ and 3 $\left(F_{1,13}=0.163, P=0.694\right)$.

\subsubsection{Correlation of physiology to behavioural expression}

WBC $(R=-0.403)$ and neutrophil count $(R=-0.520)$ were negatively correlated with GPA dimension 1 , while neutrophil: lymphocyte ratio was positively correlated $(R=0.517)$ with GPA dimension 1 . Therefore WBC and neutrophil count were lower while neutrophil: lymphocyte ratio was higher in cattle assessed as more 'agitated', 'restless' and 'anxious' (but less 'calm', 'comfortable' and 'relaxed'). 
Table 2. Terms used by observers to describe cattle behavioural expression for the flooring treatment experiment (G-NG: grip vs. nongrip flooring) and for the driving style experiment (C-SS: continuous vs. stop-start driving).

\begin{tabular}{|c|c|c|c|c|c|c|}
\hline Treatment & $\begin{array}{l}\text { GPA } \\
\text { Dimension }\end{array}$ & $\begin{array}{l}\text { Low } \\
\text { values }\end{array}$ & High values & $\begin{array}{l}\text { Treatment } \\
\text { effect }\end{array}$ & & \\
\hline \multirow[t]{3}{*}{ G-NG } & $1(46.7 \%)$ & $r<-0.6$ & $\begin{array}{l}\text { Calm (7), comfortable (5), relaxed } \\
\text { (4), at ease (2), content ( } 2) \text {, } \\
\text { predictable, settled, confident, } \\
\text { quiet, unphased, sleepy }\end{array}$ & $r>0.6$ & $\begin{array}{l}\text { Agitated (6), restless (4), anxious } \\
\text { (3), unsure (2), stressed (2), toey, } \\
\text { apprehensive, wants to leave, } \\
\text { scared, alarmed, tense, nervous, } \\
\text { uncertain, twitchy, confined, } \\
\text { panicked, flighty, worried, restricted }\end{array}$ & $\begin{array}{l}F_{1,13}=15.09, P<0.01- \\
\text { Cattle travelling on } \\
\text { non-grip flooring } \\
\text { scored higher than } \\
\text { cattle that had a metal } \\
\text { grid flooring }\end{array}$ \\
\hline & $2(12.5 \%)$ & $r<-0.5$ : & $\begin{array}{l}\text { Curious (8), interested (5), alert } \\
\text { (5), inquisitive (3), happy (2), calm } \\
\text { (2), aware (2), content, bored, } \\
\text { relaxed, quiet, concentrated, } \\
\text { bright, focussed, questioning, } \\
\text { assessing environment, } \\
\text { responsive, scared, worried }\end{array}$ & $r>0.5:$ & $\begin{array}{l}\text { Angry (3), nervous (2), upset (2), } \\
\text { shy (2), agitated (2), anxious, tired, } \\
\text { trapped, bewildered, worried, } \\
\text { oppressed, scared, frightened, } \\
\text { frustrated, sad, isolated, evasive, } \\
\text { forlorn, jumpy, alarmed, hesitant, } \\
\text { fidgety, on edge, twitchy, depressed, } \\
\text { annoyed }\end{array}$ & ns \\
\hline & $3(5.5 \%)$ & $r<-0.5$ : & $\begin{array}{l}\text { Nervous (2), bored, worried, sad, } \\
\text { thoughtful, weary, afraid, happy, } \\
\text { calm, comfortable, alone }\end{array}$ & $r>0.5:$ & $\begin{array}{l}\text { Annoyed, stressed, distressed, } \\
\text { trying to get away, inquisitive, alert, } \\
\text { revved up, playful, evasive, caring, } \\
\text { angry, seeking escape, intrigued, } \\
\text { anxious }\end{array}$ & ns \\
\hline \multirow[t]{3}{*}{ C-SS } & $1(33.3 \%)$ & $r<-0.6$ & $\begin{array}{l}\text { Calm (17), relaxed (13), } \\
\text { comfortable ( } 9 \text { ), content (5), at } \\
\text { ease (3), happy ( } 2 \text { ), quiet (2), } \\
\text { predictable, composed, afraid, } \\
\text { bored }\end{array}$ & $r>0.6$ & $\begin{array}{l}\text { Restless (8), agitated (8), scared (7), } \\
\text { anxious (7), worried (6), nervous (6), } \\
\text { stressed (5), alarmed (5), tense (5), } \\
\text { alert (5), distressed (4), frightened } \\
\text { (4), fearful (4), angry (2), unsure (2), } \\
\text { twitchy (2), bothered (2), confused } \\
\text { (2), flighty (2), trapped (2), confined } \\
\text { (2), upset (2), seeking companions, } \\
\text { boxed in, excitable, at ease, toey, } \\
\text { wants to escape, unnerved, } \\
\text { cramped, inquisitive, swamped, } \\
\text { cornered, interested }\end{array}$ & $\begin{array}{l}F_{1,13}=12.63, P<0.01- \\
\text { Cattle exposed to } \\
\text { stop-start driving } \\
\text { scored higher than } \\
\text { cattle exposed to } \\
\text { continuous driving }\end{array}$ \\
\hline & $2(16.0 \%)$ & $r<-0.5$ : & $\begin{array}{l}\text { Curious (8), interested (8), } \\
\text { inquisitive (7), alert (4), calm (3), } \\
\text { anxious (3), observant (2), relaxed } \\
\text { (2), confident (2), comfortable (2), } \\
\text { at ease (2), assessing } \\
\text { environment, happy, bright, } \\
\text { settled, questioning, bold, } \\
\text { casual, agitated, focused, seeking, } \\
\text { investigative, aware }\end{array}$ & $r>0.5:$ & $\begin{array}{l}\text { Stressed (2), tense (2), alert, } \\
\text { nervous, avoiding, irritated, worried, } \\
\text { agitated, seeking comfort, looking } \\
\text { for company, on edge, anxious, } \\
\text { panicked, angry, apprehensive, } \\
\text { frightened, annoyed, struggling }\end{array}$ & $\begin{array}{l}F_{1,13}=5.01, P<0.05- \\
\text { Cattle exposed to } \\
\text { stop-start driving } \\
\text { scored lower than } \\
\text { cattle exposed to } \\
\text { continuous driving }\end{array}$ \\
\hline & $3(8.9 \%)$ & $r<-0.5$ & $\begin{array}{l}\text { Calm (5), bored (2), intrigued (2), } \\
\text { relaxed (2), stressed, comfortable, } \\
\text { annoyed, happy, worried, } \\
\text { confined, violated, concerned, } \\
\text { stuck, unsure, indifferent, jammed, } \\
\text { agitated, tense, nervous }\end{array}$ & $r>0.5:$ & $\begin{array}{l}\text { Stressed (2), agitated, afraid, } \\
\text { frightened, comfortable, nervous, } \\
\text { aware, anxious, curious, alert, } \\
\text { relaxed }\end{array}$ & ns \\
\hline
\end{tabular}

Only terms that showed a strong negative or positive correlation (Pearson's correlation coefficient, $r$ ) with each dimension of the Generalised Procrustes Analysis (GPA) consensus profile are shown. Order of terms is determined firstly by number of observers to use that term (in parentheses where $>1$ ) and secondly by weighting (correlation, $r$ ) of each term with the GPA consensus dimensions.

We have not edited out terms that may appear on multiple lists because this would introduce subjectivity (as to which list to remove the term from), but the reader should be mindful that each individual observer had a unique list of terms and therefore how they scored the same term may to some degree be influenced by the remaining terms in their repertoire 
Table 3. Values (mean \pm SD) and statistical analyses for physiological measures collected (blood parameters, body temperature, and heart rate) for the flooring treatment experiment (grip vs. non-grip flooring).

\begin{tabular}{|c|c|c|c|c|c|c|c|c|c|c|}
\hline \multirow[t]{2}{*}{ Parameter } & \multicolumn{2}{|c|}{ Grip flooring } & \multicolumn{2}{|c|}{ Non-grip flooring } & \multicolumn{3}{|c|}{ P-value (R-M ANOVA) } & \multicolumn{3}{|c|}{$\begin{array}{c}\text { Pearson's } \mathrm{R} \text { (correlation } \\
\text { with } \\
\text { QBA scores) }\end{array}$} \\
\hline & Before & After & Before & After & $\begin{array}{l}\text { Treatment } \\
\text { Non-grip } \\
\text { flooring }\end{array}$ & $\begin{array}{c}\text { Time } \\
\text { (before } \\
\text { vs. after) }\end{array}$ & $\begin{array}{c}\text { Treatment } \\
x \\
\text { time } \\
\text { interaction }\end{array}$ & GPA 1 & GPA 2 & GPA 3 \\
\hline \multicolumn{11}{|c|}{ Hormone concentration } \\
\hline Cortisol, ng/mL & $38.5 \pm 27.5$ & $43.5 \pm 28.6$ & $43.3 \pm 30.8$ & $36.2 \pm 22.4$ & 0.507 & 0.550 & 0.550 & -0.231 & -0.247 & -0.100 \\
\hline $\begin{array}{l}\text { Insulin-like } \\
\text { growth factor, } \\
\mathrm{ng} / \mathrm{mL}\end{array}$ & $48.1 \pm 15.5$ & $51.9 \pm 14.2$ & $48.5 \pm 16.9$ & $50.0 \pm 15.7$ & 0.718 & 0.175 & 0.570 & -0.199 & 0.028 & 0.210 \\
\hline $\begin{array}{l}\text { Prolactin, } \\
\mathrm{ng} / \mathrm{mL}\end{array}$ & $25.9 \pm 18.7^{\mathrm{a}}$ & $17.7 \pm 15.6^{\mathrm{a}}$ & $39.3 \pm 24.7^{b}$ & $13.5 \pm 9.09^{\mathrm{a}}$ & 0.164 & $<0.001$ & 0.049 & -0.315 & 0.056 & 0.208 \\
\hline \multicolumn{11}{|c|}{ Metabolite concentration } \\
\hline $\begin{array}{l}\beta \text {-Hydroxy } \\
\text { butyrate, } \\
\mathrm{mmol} / \mathrm{L}\end{array}$ & $0.22 \pm 0.06$ & $0.18 \pm 0.05$ & $0.23 \pm 0.08$ & $0.22 \pm 0.05$ & 0.133 & 0.001 & 0.0502 & 0.154 & -0.224 & 0.078 \\
\hline $\begin{array}{l}\text { Glucose, } \\
\mathrm{mmol} / \mathrm{L}\end{array}$ & $5.66 \pm 0.39$ & $5.60 \pm 0.46$ & $5.60 \pm 0.38$ & $5.59 \pm 0.41$ & 0.644 & 0.582 & 0.769 & 0.207 & -0.038 & -0.349 \\
\hline \multicolumn{11}{|c|}{ Haematological parameters } \\
\hline $\begin{array}{l}\text { Red blood } \\
\text { cells, } \times 10^{9} / \mathrm{L}\end{array}$ & $8.21 \pm 0.37$ & $8.15 \pm 0.42$ & $8.26 \pm 0.50$ & $8.11 \pm 0.59$ & 0.971 & 0.215 & 0.508 & 0.046 & 0.038 & -0.127 \\
\hline Haematocrit, \% & $0.351 \pm 0.017$ & $0.348 \pm 0.019$ & $0.351 \pm 0.021$ & $0.344 \pm 0.022$ & 0.671 & 0.196 & .0588 & 0.141 & 0.095 & -0.028 \\
\hline $\begin{array}{l}\text { Haemoglobin, } \\
\text { g/L }\end{array}$ & $122 \pm 6.09$ & $120 \pm 6.50$ & $120 \pm 6.70$ & $118 \pm 5.78$ & 0.169 & 0.244 & 0.939 & 0.060 & -0.004 & -0.043 \\
\hline $\begin{array}{l}\text { White blood } \\
\text { cell, } \times 10^{9} / \mathrm{L}\end{array}$ & $9.69 \pm 0.80^{\mathrm{b}}$ & $11.4 \pm 1.90^{\mathrm{a}}$ & $9.76 \pm 1.62^{\mathrm{b}}$ & $10.19 \pm 1.50^{\mathrm{b}}$ & 0.047 & $<0.001$ & 0.015 & $-0.403^{*}$ & -0.021 & -0.003 \\
\hline $\begin{array}{l}\text { Eosinophils, } \times \\
10^{9} / \mathrm{L}\end{array}$ & $0.08 \pm 0.02$ & $0.09 \pm 0.03$ & $0.080 \pm 0.02$ & $0.076 \pm 0.02$ & 0.018 & 0.968 & 0.070 & -0.092 & 0.068 & 0.061 \\
\hline $\begin{array}{l}\text { Monocytes, } \times \\
10^{9} / \mathrm{L}\end{array}$ & $0.24 \pm 0.10$ & $0.20 \pm 0.11$ & $0.25 \pm 0.12$ & $0.21 \pm 0.12$ & 0.625 & 0.011 & 0.786 & 0.098 & 0.029 & -0.182 \\
\hline $\begin{array}{l}\text { Neutrophils, } \times \\
10^{9} / \mathrm{L}\end{array}$ & $3.01 \pm 0.55^{\mathrm{a}}$ & $4.62 \pm 1.34^{c}$ & $3.10 \pm 1.10^{\mathrm{a}}$ & $3.72 \pm 1.19^{b}$ & 0.139 & $<0.001$ & 0.025 & $-0.520^{\star \star}$ & 0.014 & 0.182 \\
\hline $\begin{array}{l}\text { Lymphocytes, } \\
\times 10^{9} / \mathrm{L}\end{array}$ & $5.46 \pm 1.00$ & $5.39 \pm 0.83$ & $5.55 \pm 0.97$ & $5.30 \pm 0.77$ & 0.998 & 0.205 & 0.463 & 0.113 & -0.071 & -0.188 \\
\hline $\begin{array}{l}\text { Neutrophil: } \\
\text { Lymphocyte } \\
\text { ratio }\end{array}$ & $0.59 \pm 0.22$ & $0.88 \pm 0.31$ & $0.57 \pm 0.21$ & $0.73 \pm 0.21$ & 0.279 & $<0.001$ & 0.200 & $0.517^{\star *}$ & -0.087 & -0.200 \\
\hline $\begin{array}{l}\text { Platelet, } \times \\
10^{9} / \mathrm{L}\end{array}$ & $565 \pm 176$ & $581 \pm 174$ & $604 \pm 159$ & $612 \pm 165$ & 0.046 & 0.336 & 0.746 & -0.116 & 0.065 & 0.081 \\
\hline \multicolumn{11}{|c|}{ Body temperature and heart rate } \\
\hline Mean $\mathrm{T}_{\text {core }},{ }^{\circ} \mathrm{C}$ & $38.60 \pm 0.150$ & $39.12 \pm 0.238^{\#}$ & $38.55 \pm 0.03$ & $39.08 \pm 0.06^{\#}$ & $<0.001$ & $<0.001$ & 0.66 & 0.085 & 0.039 & 0.125 \\
\hline $\begin{array}{l}\text { Maximum } \mathrm{T}_{\text {core, }} \\
{ }^{\circ} \mathrm{C}\end{array}$ & $38.64 \pm 0.14$ & $39.17 \pm 0.23^{\#}$ & $38.66 \pm 0.131$ & $39.12 \pm 0.24^{\#}$ & 0.146 & $<0.001$ & 0.06 & 0.031 & 0.024 & 0.133 \\
\hline $\begin{array}{l}\text { Average heart } \\
\text { rate, } 0-30 \mathrm{~min}\end{array}$ & & $107.8 \pm 42.3^{\#}$ & & $95.0 \pm 31.5^{\#}$ & & & & 0.039 & -0.350 & 0.377 \\
\hline
\end{tabular}

Correlations between physiological parameters (measured before and after each transport event) and the results of Qualitative Behavioural Analyses (Generalised Procrustes Analysis scores for each of the three main consensus dimensions) are indicated in the right-hand columns.

For raw values with significant treatment $\times$ time interactions, different letters indicate significant differences (at $P=0.05)$.

Significant effects are indicated in bold $\left({ }^{\star} P<0.05,{ }^{* *} P<0.01\right)$ for correlations with blood parameters $\left(R_{26}\right)$, body temperature $\left(R_{24}\right)$ and heart rate $\left(R_{8}\right)$.

"Indicates body temperature and heart rate measures were taken during transport. 
Table 4. Values (mean \pm SD) and statistical analyses for physiological measures collected (blood parameters, body temperature) for the driving style treatment (C-SS: continuous vs. stop-start driving).

\begin{tabular}{|c|c|c|c|c|c|c|c|c|c|c|}
\hline \multirow[t]{2}{*}{ Parameter } & \multicolumn{2}{|c|}{ Continuous } & \multicolumn{2}{|c|}{ Stop-start } & \multicolumn{3}{|c|}{ P-value (R-M ANOVA) } & \multicolumn{3}{|c|}{$\begin{array}{c}\text { Pearson's R (correlation with } \\
\text { QBA scores) }\end{array}$} \\
\hline & Before & After & Before & After & $\begin{array}{l}\text { Treatment } \\
\text { Non-grip } \\
\text { flooring }\end{array}$ & $\begin{array}{c}\text { Time } \\
\text { (before } \\
\text { vs. } \\
\text { after) }\end{array}$ & $\begin{array}{c}\text { Treatment } \\
\times \\
\text { time } \\
\text { interaction }\end{array}$ & GPA 1 & GPA 2 & GPA 3 \\
\hline \multicolumn{11}{|c|}{ Hormone concentration } \\
\hline Cortisol, ng/mL & $23.82 \pm 11.55$ & $27.59 \pm 23.27$ & $26.37 \pm 18.67$ & $31.21 \pm 32.27$ & 0.745 & 0.724 & 0.875 & 0.084 & -0.155 & $0.409^{*}$ \\
\hline $\begin{array}{l}\text { Insulin-like } \\
\text { growth factor, } \\
\text { ng/mL }\end{array}$ & $50.91 \pm 16.35$ & $51.63 \pm 14.13$ & $58.81 \pm 16.72$ & $60.17 \pm 23.49$ & 0.003 & 0.341 & 0.843 & 0.088 & -0.218 & -0.019 \\
\hline Prolactin, $\mathrm{ng} / \mathrm{mL}$ & $21.01 \pm 20.18$ & $14.53 \pm 7.58$ & $25.5 \pm 18.21$ & $22.89 \pm 17.80$ & 0.012 & 0.163 & 0.622 & -0.193 & -0.029 & -0.023 \\
\hline \multicolumn{11}{|c|}{ Metabolite concentration } \\
\hline $\begin{array}{l}\beta \text {-Hydroxy } \\
\text { butyrate, } \mathrm{mmol} / \mathrm{L}\end{array}$ & $0.21 \pm 0.06$ & $0.19 \pm 0.05$ & $0.21 \pm 0.07$ & $0.19 \pm 0.05$ & 0.958 & 0.002 & 0.937 & -0.207 & 0.263 & -0.207 \\
\hline Glucose, mmol/L & $5.52 \pm 0.27$ & $5.51 \pm 0.36$ & $5.49 \pm 0.37$ & $5.62 \pm 0.50$ & 0.587 & 0.328 & 0.149 & -0.191 & 0.005 & -0.238 \\
\hline \multicolumn{11}{|c|}{ Haematological parameters } \\
\hline $\begin{array}{l}\text { Red blood cells, } \\
\times 10^{9} / \mathrm{L}\end{array}$ & $8.22 \pm 0.45$ & $8.19 \pm 0.44$ & $8.03 \pm 0.37$ & $8.06 \pm 0.53$ & 0.008 & 0.978 & 0.634 & -0.032 & -0.342 & 0.035 \\
\hline Haematocrit, \% & $0.348 \pm 0.017$ & $0.346 \pm 0.019$ & $0.339 \pm 0.014$ & $0.340 \pm 0.021$ & 0.006 & 0.966 & 0.681 & -0.046 & -0.345 & -0.024 \\
\hline $\begin{array}{l}\text { Haemoglobin, } \\
\text { g/L }\end{array}$ & $120 \pm 5.69$ & $119 \pm 6.12$ & $117 \pm 5.35$ & $118 \pm 6.76$ & 0.025 & 0.851 & 0.483 & -0.080 & -0.329 & 0.063 \\
\hline $\begin{array}{l}\text { White blood cell, } \\
\times 10^{9} / \mathrm{L}\end{array}$ & $9.79 \pm 1.50$ & $10.87 \pm 1.46$ & $9.71 \pm 1.03$ & $10.93 \pm 1.24$ & 0.982 & $<0.001$ & 0.550 & -0.032 & -0.342 & 0.035 \\
\hline $\begin{array}{l}\text { Eosinophils, } \times \\
10^{9} / \mathrm{L}\end{array}$ & $0.085 \pm 0.028$ & $0.087 \pm 0.028$ & $0.074 \pm 0.018$ & $0.077 \pm 0.019$ & 0.007 & 0.493 & 0.877 & -0.046 & -0.180 & -0.069 \\
\hline $\begin{array}{l}\text { Monocytes, } \times \\
10^{9} / \mathrm{L}\end{array}$ & $0.429 \pm 0.433$ & $0.362 \pm 0.410$ & $0.356 \pm 0.277$ & $0.257 \pm 0.265$ & 0.183 & $<0.001$ & 0.490 & -0.280 & 0.015 & 0.119 \\
\hline $\begin{array}{l}\text { Neutrophils, } \times \\
10^{9} / \mathrm{L}\end{array}$ & $2.77 \pm 0.972$ & $3.88 \pm 1.19$ & $2.80 \pm 0.553$ & $4.03 \pm 0.979$ & 0.728 & $<0.001$ & 0.444 & -0.027 & $-0.429 *$ & 0.078 \\
\hline $\begin{array}{l}\text { Lymphocytes, } \times \\
10^{9} / \mathrm{L}\end{array}$ & $5.56 \pm 0.629$ & $5.39 \pm 0.607$ & $5.41 \pm 0.697$ & $5.22 \pm 0.668$ & 0.123 & 0.106 & 0.886 & 0.347 & 0.045 & -0.032 \\
\hline $\begin{array}{l}\text { Neutrophil: } \\
\text { Lymphocyte } \\
\text { ratio }\end{array}$ & $0.500 \pm 0.170$ & $0.728 \pm 0.245$ & $0.526 \pm 0.130$ & $0.795 \pm 0.271$ & 0.263 & $<0.001$ & 0.559 & 0.126 & 0.345 & -0.151 \\
\hline Platelet, $\times 10^{9} / \mathrm{L}$ & $629 \pm 151$ & $620 \pm 163$ & $642 \pm 167$ & $638 \pm 162$ & 0.204 & 0.508 & 0.841 & 0.001 & -0.332 & 0.183 \\
\hline \multicolumn{11}{|c|}{ Body temperature and heart rate } \\
\hline Mean $\mathrm{T}_{\text {core }},{ }^{\circ} \mathrm{C}$ & $38.63 \pm 0.10^{a}$ & $38.85 \pm 0.38^{\mathrm{b \#}}$ & $38.62 \pm 0.10^{\mathrm{a}}$ & $39.04 \pm 0.32^{\text {c\# }}$ & $<0.001$ & $<0.001$ & $<0.001$ & -0.038 & 0.215 & -0.121 \\
\hline $\begin{array}{l}\text { Maximum } \mathrm{T}_{\text {core }} \\
{ }^{\circ} \mathrm{C}\end{array}$ & $38.67 \pm 0.10^{\mathrm{a}}$ & $38.91 \pm 0.36^{\mathrm{b \#}}$ & $38.67 \pm 0.11^{\mathrm{a}}$ & $39.07 \pm 0.34^{\mathrm{c \#}}$ & 0.008 & 0.008 & 0.002 & -0.033 & 0.219 & -0.041 \\
\hline
\end{tabular}

Correlations between physiological parameters (measured before and after each transport event) and the results of Qualitative Behavioural Analyses (Generalised Procrustes Analysis scores for each of the three main consensus dimensions) are indicated in the right-hand columns.

For raw values with significant treatment $\times$ time interactions, different letters indicate significant differences $($ at $P=0.05)$.

Significant effects are indicated in bold $\left({ }^{\star} P<0.05,{ }^{\star \star} P<0.01\right)$ for correlations with blood parameters $\left(R_{26}\right)$, body temperature $\left(R_{24}\right)$.

\#Indicates body temperature and heart rate measures were taken during transport. 


\subsection{Experiment 2: continuous vs. stop-start driving style}

\subsubsection{Physiology}

A summary of the raw values, results of R-M ANOVA and correlation with GPA dimension scores is given in Table 4.

A significant treatment $\times$ time interaction was found for mean and maximum $T_{\text {core }}$, with an elevation over time which were greater during SS driving compared with the same animals exposed to C driving.

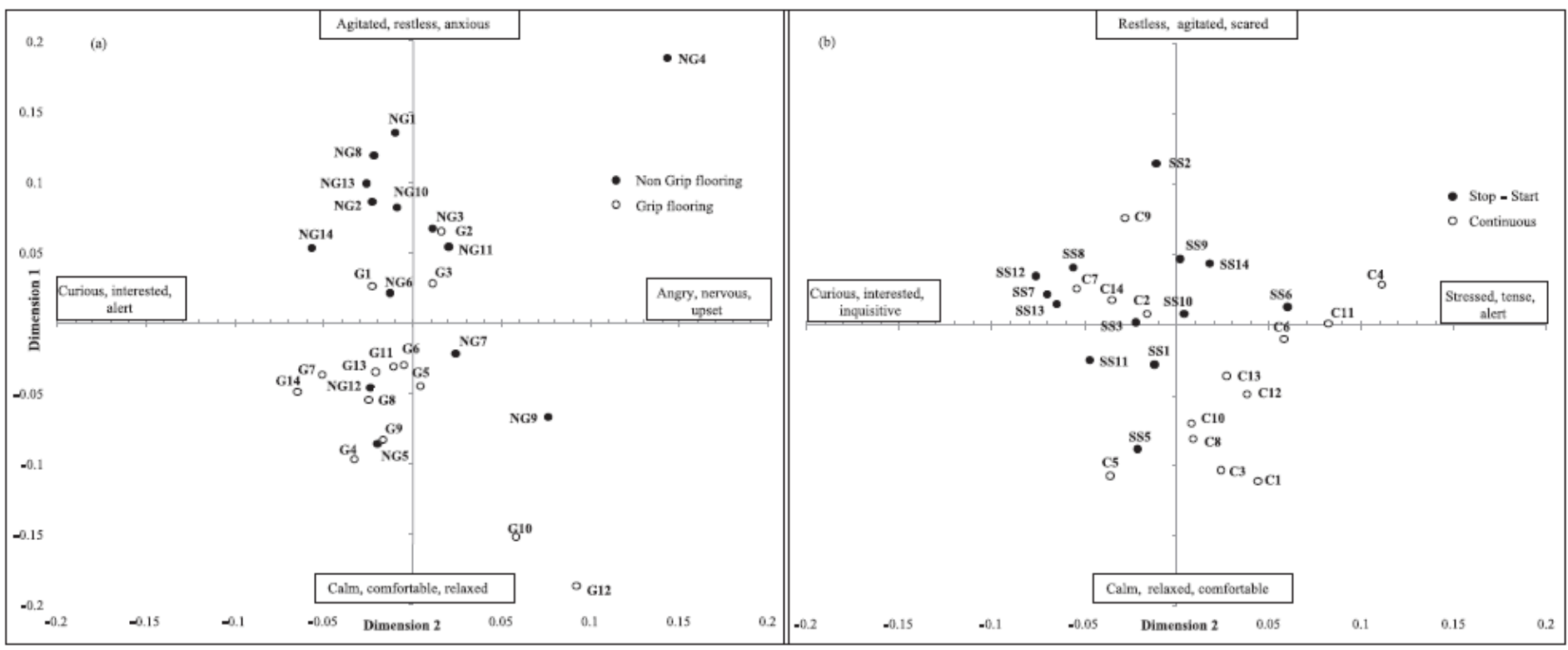

Fig. 1. Example of a word map of consensus profile for Generalised Procrustes Analysis (GPA) dimensions 1 and 2 for one observer viewing cattle from (a) Experiment 1: the flooring treatment experiment (G-NG: grip vs. non-grip flooring) and (b) Experiment 2: for the driving style experiment (C-SS: continuous vs. stop-start driving).

Being transported (i.e. a significant time effect: before transport vs. after transport) resulted in a decrease in monocyte count, and $\beta$-hydroxy butyrate concentration, as well as an increase in WBC, neutrophil count, neutrophil: lymphocyte ratio and Tcore (note that, with the exception of prolactin, which decreased in response to NG transport, the same responses were observed for Experiment 1).

\subsubsection{Qualitative Behavioural Assessment}

The Procrustes Statistic generated for GPA analysis of the C-SS treatments (39.4\%) differed significantly $\left(t_{99}=43.95, P<0.001\right)$ from a mean randomised profile $(32.1 \pm 0.2 \%)$. Three main GPA dimensions were identified, explaining a total of $58.2 \%$ of the variation between animals (Table 2 ).

Terms with the strongest correlation with each of the GPA dimensions are shown in Table 2. For GPA dimension 1, low values were associated with terms such as 'calm', 'relaxed' and 'comfortable' and high values with terms such as 'restless', 'agitated' and 'scared'. For GPA dimension 2, low values were associated with terms such as 'curious', 'interested' and 'inquisitive' and high values with terms such as 'stressed', 'tense' and 'alert'. For GPA dimension 3, low values were associated with terms such as 'calm', 'bored' and 'intrigued' and high values with terms such as 'stressed', 'agitated' and 'afraid'.

The positions of individual cattle on the first two GPA dimensions are shown in Fig. 2b. Cattle exposed to SS driving scored significantly greater values on GPA dimension $1\left(F_{1,13}=12.63, P<0.001\right)$ and smaller 
values on GPA dimension $2\left(F_{1,13}=5.01, P<0.05\right)$ than cattle exposed to $C$ driving; however, there were no treatment effects on GPA dimension $3\left(F_{1,13}=2.91, P=0.11\right)$.

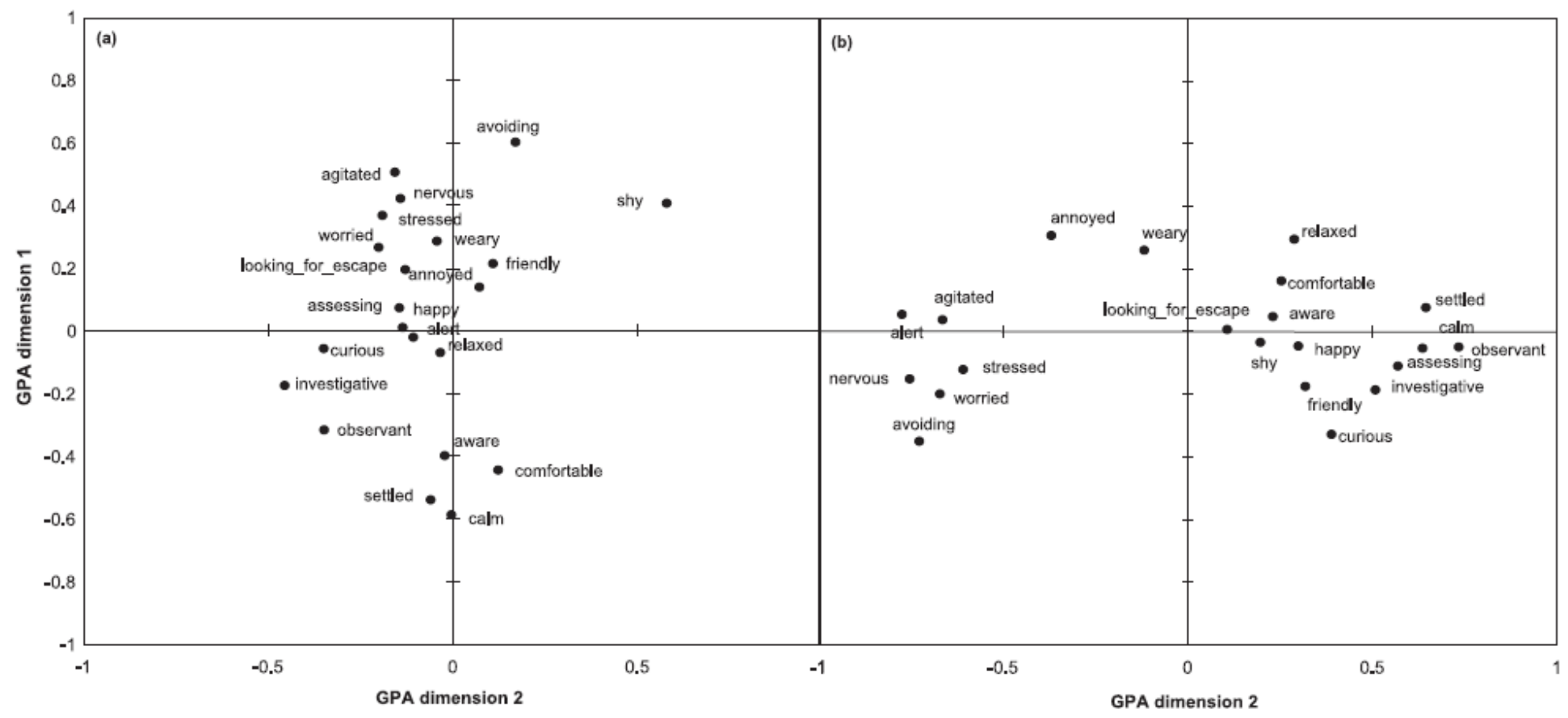

Fig. 2. Positions of individual cattle (represented by numbers) on Generalised Procrustes Analysis dimensions 1 and 2 obtained from Qualitative Behavioural Assessment. Each animal (numbers are individual ID codes) is represented twice on each graph, once for each experimental transport event, where the datum position indicates its scores on each GPA axis. (a) Experiment 1: flooring treatment experiment (G: grip flooring open circles and NG: non-grip flooring closed circles), and (b) Experiment 2: driving style experiment (C: continuous driving open circles and SS: stop-start driving closed circles).

\subsubsection{Correlation of physiology to behavioural expression}

Neutrophil count $(R=-0.429)$ was negatively correlated with GPA dimension 2 and were therefore lower for cattle also described as more 'stressed', 'tense' and 'alert' (less 'curious', 'interested' and 'inquisitive'). Plasma cortisol concentrations were positively correlated $(R=0.409)$ with GPA dimension 3 and were therefore greater for cattle assessed as more 'stressed', 'agitated' and 'afraid' (or less 'calm', 'bored' and 'intrigued').

\section{Discussion}

There was consensus between observers in regard to their assessments of behavioural expression of the cattle in the flooring treatment (G-NG flooring; Experiment 1) and the driving style (C-SS driving; Experiment 2) experiments, with the GPA consensus profile explaining just under half the variation in scores between the observers. Other studies have similarly found consensus between observers indicating that people see common dimensions of animal behavioural expression. This has been demonstrated for on-farm qualitative assessments of veal calves following milk distribution (Brscic et al., 2009), dairy cows in a loose housing system (Rousing and Wemelsfelder, 2006) and beef cattle during road transport (Stockman et al., 2011), as well as for other species [pigs (Rutherford et al., 2012; Temple et al., 2011; Wemelsfelder et al., 2000, 2001, 2009), horses (Minero et al., 2009; Napolitano et al., 2008), 
sheep (Wickham et al., 2012), poultry (Wemelsfelder, 2007) and dogs (Walker et al., 2010)]. The consensus between observers is an important aspect of QBA, as it indicates that the descriptive terms chosen by each observer gave a coherent basis for scoring the behavioural expressions of animals and the observers based their assessment on commonly-perceived and systematically-applied criteria.

There were some significant differences in observer scores between treatments. For Experiment 1, cattle exposed to NG flooring were scored as more 'agitated', 'restless' and 'anxious' compared with cattle that had G flooring (more 'calm', 'comfortable' and 'relaxed' on GNG GPA dimension 1). These data suggest that the ability of cattle to balance during road transport influences the behavioural expression of cattle. These results support previous studies that have recorded altered animal behavior depending on how a vehicle is driven: acceleration, braking, cornering and vibrations affect the movement of the vehicle and in turn the ability of the animals onboard to maintain their balance and posture (e.g. Eldridge et al., 1988; Tarrant and Grandin, 2000; Tarrant et al., 1992). For example, sheep experience fewer losses of balance, increased lying behaviour, more rumination and fewer disturbances when travelling on a motorway journey compared with single carriageway driving, most likely due to less acceleration, braking and cornering on a motorway (Cockram et al., 2004).

For Experiment 2, the cattle were scored as more 'restless', 'agitated' and 'scared' (C-SS GPA dimension 1) or 'curious', 'interested' and 'inquisitive' (C-SS GPA dimension 2) when they were filmed during SS driving. By contrast, when they were filmed during the $C$ driving event, cattle were described as more 'calm', 'relaxed' and 'comfortable' (C-SS GPA dimension 1), or more 'stressed', 'tense' and 'alert' (C-SS GPA dimension 2). Although the result for GPA dimension 2 may seem counterintuitive, GPA dimension 2 had less power of explanation for the variation between animals (16\%). It is interesting that 'alert' appeared on both the low value and high value side for dimension 2. Some observers applied this term to cattle that were also described as highly curious and interested in their surroundings whilst others used it to describe cattle that were also scored highly for the terms stressed and tense. This suggests that the term 'alert' is not helpful in deciding the overall welfare status of cattle because its meaning is quite ambiguous and does not clearly indicate a positive or negative welfare state.

We recorded physiological changes in our cattle which suggested that they experienced varying degrees of stress in response to the transport treatments. For both experiments, transport resulted in a decrease in monocyte count and $\beta$-hydroxy butyrate concentration, as well as an increase in white blood cell count, neutrophil count and neutrophil: lymphocyte ratio. Changes in circulating white blood cell values in response to road transport has also been found in cattle in previous studies, as indicated by an increase in WBC and neutrophils and a decrease in the number of lymphocytes, eosinophils and monocytes (Kent and Ewbank, 1983; Schaefer et al., 1997; Tarrant et al., 1992). The response of prolactin was not predicted, given past studies that have found an increase in prolactin concentration in response to stress (Johke, 1970; Raud et al., 1971); however, it has not been studied in cattle in the context of transport. In the present study, mean and maximum $\mathrm{T}_{\text {core }}$ increased in cattle in response to transport. An increase in $\mathrm{T}_{\text {core }}$ above the normal range may reflect greater muscular exertion to maintain and regain balance during braking, gear changes and cornering during stop-start driving, since animals standing on four legs have difficulty in dealing with disturbances such as those caused by swinging around corners or sudden braking (Broom, 2007). They do not lean on other individuals and are significantly disturbed by too much movement (Broom, 2007).

Not all physiological variables measured demonstrated significant treatment effects. For example, we did not record significant treatment effects on cortisol in either study, this may reflect sampling times (before and after 90 min transport, which may miss a potential acute peak in cortisol concentration during transport) (see also Wickham et al., 2012). While there are no treatment effects in these physiological 
measures, individual differences may still reveal important individual responses that were correlated with behavioural expression.

Importantly, aspects of the behavioural expression of cattle were statistically significantly correlated with physiological changes in meaningful ways. For example, WBC and neutrophil counts were depressed while the neutrophil: lymphocyte ratio was elevated for cattle described as more 'agitated', 'restless', and 'anxious' (G-NG GPA dimension 1) and neutrophil count was similarly correlated with C-SS GPA dimension 2 (being higher for animals also scored as more 'stressed', 'tense' and 'alert'). Plasma cortisol concentrations were greater in cattle also assessed as more 'stressed', 'agitated' and 'afraid' (C-SS GPA dimension 3). These results suggest that the QBA process detected behavioural manifestations of stress in cattle during transport. The strength of these correlations may have been improved with a greater sample size, which was limited due to space on the trailer as well as problems with unreliable equipment (heart rate monitors).

In summary, QBA appears to be a valid, repeatable method of assessing cattle welfare during land transport. Firstly, we have demonstrated that observers reach consensus in how they score the behavioural expression of cattle, using terms that are semantically consistent. Secondly, the method allows discrimination between treatment groups, even when observers are not made aware of these treatment groups, indicating that subtle differences in behavioural expression could be detected. Finally, the behavioural expression scores are meaningfully correlated with various physiological parameters, providing further support for the biological validity of QBA, and for the relevance of QBA to animal welfare assessment.

QBA allows whole-animal assessment in an integrative sense. It takes into account how an animal interacts with its environment. This is an important consideration in applying the technique across different industry situations. The extension of the present study to commercial conditions is likely to require the establishment of fixed lists of terms appropriate for each context, as has been done by assessors applying QBA to assess cattle under various on-farm conditions in Europe (e.g. Brscic et al., 2009). In Australia, it is recommended by industry that 'livestock handlers should have experience in animal handling to ensure welfare of cattle in their charge' (Standing Committee on Agricultural and Resource Management, 2002). This experience recognises the handlers' ability to undertake assessment of behavioural expressions of animals in much the same manner as we have quantified in the present study. Training assessors in the QBA method could therefore formalise and encourage stockmanship skills for both road transport and other livestock industries. In conclusion, QBA may be useful as an aid to interpretation of more detailed welfare measures, or to highlight situations that require more intensive welfare assessment, particularly in animal production scenarios where more invasive welfare assessments are difficult to implement.

\section{Acknowledgements}

Thanks to T. Tan from Murdoch University Production Animal Unit for help with surgical procedures and M. Dionisio and P. McGilchrist for their help during experiments. Thanks to Murdoch University farm staff, Kim Thomas (manager) and Don Hook. Thanks also to Murdoch University Veterinary Clinical Pathology and M. Blackberry at the University of Western Australia, School of Animal Biology for blood analyses. Thanks to the observers who participated in this study. This study was funded by Meat and Livestock Australia and Meat \& Wool New Zealand. 


\section{References}

Barnes, M.A., Carter, R.E., Longnecker, J.V., Riesen, J.W., Woody, C.O., 1975. Age at transport and calf survival. J. Dairy Sci. 58, 1247.

Beatty, D.T., Barnes, A., Taylor, E., Pethick, D., McCarthy, M., Maloney, S.K., 2006. Physiological responses of Bos taurus and Bos indicus to prolonged, continuous heat and humidity. J. Anim. Sci. 84, 972-985.

Breier, B.H., Gallaher, B.W., Gluckman, P.D., 1991. Radioimmunoassay for insulin-like growth factor-l: solutions to some potential problems and pitfalls. J. Endocrinol. 128, 347-357.

Broom, D.M., 2007. Causes of poor welfare and welfare assessment during handling and transport. In: Grandin, T. (Ed.), Livestock Handling and Transport, CAB International, Wallingford, pp. 30-43.

Brscic, M., Wemelsfelder, F., Tessitore, E., Gottardo, F., Cozzi, G., Van Reenen, C.G., 2009. Welfare assessment: correlations and integration between a Qualitative Behavioural Assessment and a clinical/health protocol applied in veal calves farms. Proceedings of the 18th National Congress ASPA Palermo, Italy. Ital. J. Anim. Sci. 8, 601-603.

Dawkins, M.S., 2003. Behaviour as a tool in the assessment of animal welfare. Zoology 106, 383-387.

Dijksterhuis, G.B., Heiser, W.J., 1995. The role of permutation tests in exploratory multivariate data analysis. Food Qual. Pref. 6, 263-270.

Eldridge, G.A., Winfield, C.G., Cahill, D.J., 1988. Responses of cattle to different space allowances, pen sizes and road conditions during transport. Aust. J. Exp. Ag. 28, 155-159.

Grigor, P.N., Cockram, M.S., Steele, W.B., Le Sueur, C.J., Forsyth, R.E., Guthrie, J.A., Johnson, A.K., Sandilands, V., Reid, H.W., Sinclair, C., Brown, H.K., 2001. Effects of space allowance during transport and duration of mid-journey lairage period on the physiological, behavioural and immunological responses of young calves during and after transport. Anim. Sci. 73, 341-360.

Honma, K.-I., von Goetz, C., Aschoff, J., 1983. Effects of restricted daily feeding on free-running circadian rhythms in rats. Physiol. Behav. 30, 905-913.

Johke, T., 1970. Factors affecting the plasma prolactin level in the cow and the goat as determined by radioimmunoassay. Endocr. Jap. 17, 393-396.

Jones, M., Allison, R., 2007. The ruminant complete blood count - evaluation and interpretation, CanWest Veterinary Conference, Banff, Alberta.

Kendrick, K.M., 2007. Quality of life and the evolution of the brain. Animal Welfare 16, 9-15.

Kent, J.E., Ewbank, R., 1983. The effect of road transportation on the blood constituents and behaviour of calves. I. Six months old. Brit. Vet. J. 139, 228-235.

Knowles, T.G., 1999. A review of the road transport of cattle. Vet. Rec. 144, 197-201.

Le Neindre, P., Terlouw, C., Boivin, X., Bossy, A., Lensink, J., 2001. Behavioural research and its application to livestock transport and policy: A European perspective. J. Anim. Sci. 76, E159E165.

Mellor, D.J., 2012. Animal emotions, behaviour and the promotion of positive welfare states. N. Z. Vet. J. 60, 1-8.

Minero, M., Tosi, M.V., Canali, E., Wemelsfelder, F., 2009. Quantitative and qualitative assessment of the response of foals to the presence of an unfamiliar human. Appl. Anim. Behav. Sci. 116, 74-81.

Murata, H., Hirose, H., 1990. Impairment of lymphocyte blastogenesis in road-transported calves observed with a whole blood culture technique. Jap. J. Vet. Sci. 52, 183-185.

Murata, H., Hirose, H., 1991. Suppression of bovine lymphocyte and macrophage functions by sera from roadtransported calves. Brit. Vet. J. 147, 455-462.

Napolitano, F., De Rosa, G., Braghieri, A., Grasso, F., Bordi, A., Wemelsfelder, F., 2008. The qualitative assessment of responsiveness to environmental challenge in horses and ponies. Appl. Anim. Behav. Sci. 109, 342-354.

Piccione, G., Caola, G., 2002. Biological rhythm in livestock. J. Vet. Sci. 3, 145-157. 
Raud, H.R., Kiddy, C.A., Odell, W.D., 1971. The effect of stress upon the determination of serum prolactin by radioimmunoassay. Proc. Soc. Exp. Biol. Med. 136, 689-692.

Rousing, T., Wemelsfelder, F., 2006. Qualitative assessment of social behaviour of dairy cows housed in loose housing systems. Appl. Anim. Behav. Sci. 101, 40-53.

Rutherford, K.M.D., Donald, R.D., Lawrence, A.B., Wemelsfelder, F., 2012. Qualitative Behavioural Assessment of emotionality in pigs. Appl. Anim. Behav. Sci. 139, 218-224.

Schaefer, A.L., Jones, S.D., Stanley, R.W., 1997. The use of electrolyte solutions for reducing transport stress. J. Anim. Sci. 75, 258-265.

Scott-Moncrieff, J.C., Koshko, M.A., Brown, J.A., Hill, K., Refsal, K.R., 2003. Validation of a chemiluminescent enzyme immunometric assay for plasma adrenocorticotropic hormone in the dog. Vet. Clin. Path. 32, 180-187.

Standing Committee on Agricultural and Resource Management, 2002. Australian model code of practice for the welfare of animals: land transport of cattle. In: Publishing, C. (Ed.), SCARM Report, p. 77.

Stockman, C.A., Collins, T., Barnes, A.L., Miller, D., Wickham, S.L., Beatty, D.T., Blache, D., Wemelsfelder, F., Fleming, P.A., 2011. Qualitative behavioural assessment of cattle naïve and habituated to road transport. Anim. Prod. Sci. 51, 240-249.

Sutton, J.R., Casey, J.H., 1975. The adrenocortical response to competitive athletics in veteran athletes. J. Clin. Endocrinol. Metab. 40, 135-138.

Tarrant, P.V., 1990. Transportation of cattle by road. Appl. Anim. Behav. Sci. 28, 153-170.

Tarrant, P.V., Grandin, T., 2000. Cattle transport. In: Grandin, T. (Ed.), Livestock handling and transport. CAB International, Wallingford, pp. 109-126.

Tarrant, P.V., Kenny, F.J., Harrington, D., Murphy, M., 1992. Long distance transportation of steers to slaughter: effect of stocking density on physiology, behaviour and carcass quality. Livestock Prod. Sci. 30, 223-238.

Temple, D., Manteca, X., Velarde, A., Dalmau, A., 2011. Assessment of animal welfare through behavioural parameters in Iberian pigs in intensive and extensive conditions. Appl. Anim. Behav. Sci. 131, 29-39.

Thomas, C.K., Pearson, R.A., 1986. Effects of ambient temperature and head cooling on energy expenditure, food intake and heat tolerance of Brahman and Brahman $\times$ Friesian cattle working on treadmills. Anim. Sci. 43, 83-90.

Tindal, J.S., Knaggs, G.S., Hart, I.C., Blake, L.A., 1978. Release of growth hormone in lactating and nonlactating goats in relation to behaviour, stages of sleep, electroencephalograms, envrionmental stimuli and levels of prolactin, insulin, glucose and free fatty acids in the circulation. J. Endocrinol. 76, 333-346.

Trunkfield, H.R., Broom, D.M., 1990. The welfare of calves during handling and transport. Appl. Anim. Behav. Sci. 28, 135-152.

Walker, J., Dale, A., Waran, N., Clarke, N., Farnworth, M., Wemelsfelder, F., 2010. The assessment of emotional expression in dogs using a Free Choice Profiling methodology. Anim. Welf. 19, 75-84.

Warriss, P.D., Brown, S.N., Knowles, T.G., Kestin, S.C., Edwards, J.E., Dolan, S.K., Phillips, A.J., 1995. Effects on cattle of transport by road for up to 15 hours. Vet. Rec. 136, 319-323.

Wemelsfelder, F., 2007. How animals communicate quality of life: the qualitative assessment of behaviour. Anim. Welf. 16, 25-31.

Wemelsfelder, F., Hunter, A.E., Paul, E.S., Lawrence, A.B., 2012. Assessing pig body language: agreement and consistency between pig farmers, veterinarians and animal activists. J. Anim. Sci. 90, 3652-3665.

Wemelsfelder, F., Hunter, E.A., Mendl, M.T., Lawrence, A.B., 2000. The spontaneous qualitative assessment of behavioural expressions in pigs: first explorations of a novel methodology for integrative animal welfare measurement. Appl. Anim. Behav. Sci. 67, 193-215. 
Wemelsfelder, F., Hunter, T.E.A., Mendl, M.T., Lawrence, A.B., 2001. Assessing the 'whole animal': a free choice profiling approach. Anim. Behav. 62, 209-220.

Wemelsfelder, F., Nevison, I., Lawrence, A.B., 2009. The effect of perceived environmental background on qualitative assessments of pig behaviour. Anim. Behav. 78, 477-484.

Wemelsfelder, F., Lawrence, A.B., 2001. Qualitative assessment of animal behaviour as an on-farm welfare-monitoring tool. Acta Agriculturae Scandinavica, Section A: Animal Science Suppl. 30, 21-25.

Wickham, S.L., Collins, T., Barnes, A.L., Miller, D., Beatty, D.T., Stockman, C., Blache, D., Wemelsfelder, F., Fleming, P.A., 2012. Qualitative behavioural assessment of transport-naïve and transporthabituated sheep. J. Anim. Sci. In Press [Epub ahead of print].

Wythes, J.R., 1985. Cattle transportation strategies. Proceedings of the First National Grazing Animal Welfare Symposium. Australian Veterinary Association, Brisbane, Australia.

Yeates, J.W., Main, D.C.J., 2008. Assessment of positive welfare: a review. Vet. J. 175, 293-300. 